\title{
Evidence, ethics, hubris and the future of second-hand smoke policy
}

\section{Simon Chapman}

\section{Smoke-free workplaces and public places - the ongoing debate}

T he news that French bars and restaurants will be smoke free by the end of 2007 led to hundreds of headlines, impelled by a "myth turned on its head" subtext. The tedious cliché that every second French citizen's birthright requires them to sit in cafes smoking Gauloises and sipping pastis while reading Jean-Paul Sartre is about as accurate today as the view that Ireland is a nation of potato diggers or that all Italians obey the Pope's dictums on contraception. Smokers have long been a minority in all three of these countries. Nonetheless, an "if they can, anyone can" incredulity has made these three nations' decisions to ban smoking in bars globally newsworthy. Californian leadership was vital, but discounted by reasoning that alluded to their reputation for having all sorts of eccentric proclivities when it comes to diet and health. If, as expected, France follows the Irish and Italian experience with only minor enforcement problems and failure of the bar economy to collapse, ${ }^{12}$ doomsayers in the tobacco industry and its third-party acolytes will surely have nowhere to turn in halting the global domino effect.

But there are worrying signs in the euphoria of what has now become almost predictable, repeated policy success. A small minority on the fringe of tobacco control are starting to hand hostages to fortune and abandon the sacrosanct ethi$\mathrm{Cal}^{3}$ and evidence-based principles that underpin all good public health policy.

The global push for smoke-free workplaces and public spaces was built on a bedrock of research about second-hand smoke (SHS) being harmful. Door-stopper-sized review volumes ${ }^{4}$ have synthesised this evidence, which has, with rare exceptions, been gathered from studying those who have been chronically exposed in indoor domestic and workplace settings. Some experimental work has shown that even brief, acute exposure to SHS can cause measurable physiological changes in people exposed to it..$^{5}$ This evidence has been important in demonstrating the basis on which cumulative exposure is pathogenic.
However, the 2006 US Surgeon General's report on The health consequences of involuntary exposure to tobacco smoke was cautious in the way it described the evidence on the acute effects of exposure to SHS, stating "The evidence is suggestive but not sufficient to infer a causal relationship between SHS exposure and acute respiratory symptoms including cough, wheeze, chest tightness, and difficulty breathing" among people with asthma as well as among healthy people. ${ }^{4}$ Cumulative exposure is harmful, but the deleterious effects of acute exposure require further research before we can agree that it is truly harmful.

As smoking becomes exiled outdoors, reasonable debates have emerged about banning smoking in outdoor, roofless areas where lots of people gather in sardine-tin-like densities. ${ }^{5}$ Sports stadia are now increasingly smoke free, with little protest occurring because what is being regulated is so reasonable. The unpleasant and sometimes distressing experience of sitting for hours next to smokers at sports events and concerts is a common experience. Smokers can see the distress they cause, and few are keen to defend the indefensible when moving well away to smoke has now become routine etiquette.

Equally reasonable debates are also occurring about the unintended effect of indoor smoking bans in concentrating smoking in the outdoor, alfresco sections of restaurants and bars where similar cheek-by-jowl seating causes patrons to be again half pickled in smoke. Policies are also emerging to prevent building entrances becoming log jams of smokers through which the public and non-smoking workers must navigate.

In each of the above scenarios, arguments about amenity and the unreasonableness of many smokers have been at the heart of moving policy further along. ${ }^{6}$ Typical regulations specify that smoking areas should be a minimum of $5 \mathrm{~m}$ away from building entrances. But for some in tobacco control, this is not enough. They want public policy to prevent the possibility of any involuntary exposure, no
Smoking, they argue, should be banned from pavements, parks, beaches, the open decks of ocean cruise liners and dedicated smoking rooms at airports (because of leakage when smokers come and go from these rooms). In such circles, it has become almost profane to ask where smokers might be allowed to light up.

In one unforgettable tobacco control list-server exchange in 2005, some argued for policies that banned smokers from employment because smoke on the breath and clothes "off-gassed" particles when they returned into a building after smoking, (something Invernizzi et al have since shown is measurable in smokers' breath only for an average of $58.6 \mathrm{~s}$ ). By the logic of the same argument, smokers would presumably be forbidden from using public transport, attending cinemas or indeed ever mixing with non-smokers. Their children could be taken from them for their own good, the reductio ad absurdum would run. Undeterred by the scorn poured on such suggestions, some correspondents unashamedly added that the threat of unemployment was a fine example of enlightened paternalism: smokers should be virtually forced to quit for their own good.

Individuals claiming to be badly affected by even the smallest encounters with tobacco smoke in outdoor settings are often impassioned advocates for outdoor smoking bans. Their arguments typically describe florid symptoms and lives ruined by their inability to mix in society. They invoke the compelling frames of injustice used by oppressed people whose concerns are ignored and argue that claims about lack of evidence effectively deny the reality of their lived experience. They often claim roles for themselves as Gallilean-like truth tellers, heroically banging on the cosseted, doctrinal doors of science. They like to remind us of Schopenhauer's advice that "All truth passes through three stages. First, it is ridiculed. Second, it is violently opposed. Third, it is accepted as being self-evident." Anyone expressing scepticism that, in the carbon particle soup in which we live today, specific intolerance of tobacco smoke at levels encountered outdoors sounds implausible risks being branded as a tobacco industry stooge.

When a person tells you he or she is ill, the humane and caring response requires total sympathy and acquiescence to their requests for help. But in understanding any disease, it is never sufficient that we simply take the sufferer's word as being all we need to know. Subjecting claims about exquisite environmental sensitivities to standard tests of evidence and 
causality is reasonable, and, if the draconian scenarios I have described for smokers were to ever be on the policy table, also absolutely essential.

Staudenmayer et al have examined the evidence for idiopathic environmental intolerance (IEI; embracing environmental illness, multiple chemical sensitivity and chemical intolerance) against Bradford Hill's nine criteria (strength, consistency, specificity, temporality, biological gradient, biological plausibility, coherence, experimental intervention and analogy) and an additional criterion (reversibility). They concluded that toxicogenic theory fails all these criteria, with there being "no convincing evidence to support the fundamental postulate that IEI has a toxic aetiology" and that "the hypothesised biological processes and mechanisms are implausible" ${ }^{8}$ Moreover, they also concluded that "psychogenic theory meets all of the criteria directly or indirectly", being "characterised by a progressive research programme including double-blind, placebo-controlled provocation challenge studies". They concluded "that IEI is a belief characterised by an overvalued idea of toxic attribution of symptoms and disability, fulfilling criteria for a somatoform disorder and a functional somatic syndrome. A neurobiological diathesis similar to anxiety, specifically panic disorder, is a neurobiologically plausible mechanism to explain triggered reactions to ambient doses of environmental agents, real or perceived. In addition, there is a cognitively mediated fear response mechanism characterised by vigilance for perceived exposures and bodily sensations that are subsequently amplified in the process of learned sensitivity." 9

Those with claimed hypersensitivity to even homeopathic-like strength exposures to SHS claim that tobacco smoke is a special case which, unlike other environmental carbon particle pollution, would satisfy the criteria for toxicogenic theories of IEI. Such exceptionalism is highly unlikely to be the case.

In tobacco control's armoury, there are few more potent weapons in driving down tobacco use than restrictions on smoking premised on evidence of harm to others. ${ }^{10}$ If this evidence base is not vigilantly respected and the arguments for tobacco control are allowed to haemorrhage into the moralism that characterised tobacco control of previous centuries, globalised communication will rapidly pass news of this regression and risk undermining the global adoption of the policies we now take for granted in many western nations. Equally, if anyone in tobacco control believes that untethered paternalism that abandons ethical respect for smokers to harm themselves has broad appeal, their hubris awaits its inevitable fate.

\section{Tobacco Control 2007; 16:73-74. doi: 10.1136/tc.2007.020552}

\section{Correspondence to: Professor S Chapman,} School of Public Health, University of Sydney, Sydney, NSW 2006, Edward Ford Building A27, Australia; sc@med.usyd.edu.au
Competing interests: None declared.

\section{REFERENCES}

1 Howell F. Smoke-free bars in Ireland: a runaway success. Tob Control 2005;14:73-4.

2 Galeone D, Laurendi G, Vasselli S, et al. Preliminary effects of Italy's ban on smoking in enclosed public places. Tob Control 2006;15:143.

3 Cole P. The moral bases for public health interventions. Epidemiology 1994;6:78-83.

4 US Department of Health and Human Services. The health consequences of involuntary exposure to tobacco smoke: a report of the Surgeon General, US Department of Health and Human Services, Centers for Disease Control and Prevention, Coordinating Center for Health Promotion, National Center for Chronic Disease Prevention and Health Promotion, Office on Smoking and Health, 2006.

5 Celermajer DS, Adams MR, Clarkson P, et al. Passive smoking and impaired endotheliumdependent arterial dilatation in healthy young adults. N Engl J Med 1996;334:150-4.

6 Chapman S. For debate: banning smoking outdoors is seldom ethically justified. Tobacco Control 2000:9:95-7.

7 Invernizzi G, Ruprecht A, De Marco C, et al. Residual tobacco smoke: measurement of its washout time in the lung and of its contribution to environmental tobacco smoke. Tobacco Control 2007; 16:29-33.

8 Staudenmayer $\mathrm{H}$, Binkley KE, Leznoff $\mathrm{A}$, et al. Idiopathic environmental intolerance: Part 1: A causation analysis applying Bradford Hill's criteria to the toxicogenic theory. Toxicol Rev 2003;22:235-46.

9 Staudenmayer $\mathbf{H}$, Binkley KE, Leznoff A, et al. Idiopathic environmental intolerance: Part 2: A causation analysis applying Bradford Hill's criteria to the psychogenic theory. Toxicol Rev 2003:22:247-61.

10 Alamar B, Glantz SA. Effect of increased social unacceptability of cigarette smoking on reduction in cigarette consumption. Am J Public Health 2006;96:1359-63.

\section{BNF for Children 2006, second annual edition}

In a single resource:

- guidance on drug management of common childhood conditions

- hands-on information on prescribing, monitoring and administering medicines to children

- comprehensive guidance covering neonates to adolescents

For more information please go to bnfc.org 